Portellano-Ortiz C, Conde-Sala JL. Cognition and its association with the factors of the EURO-D: Suffering and Motivation. Findings from SHARE Wave 6. International Journal of Geriatric Psychiatry 2018. (Accepted July 31)

\title{
Cognition and its association with the factors of the EURO-D: Suffering and Motivation. Findings from SHARE Wave 6.
}

Running title: Cognition and EURO-D factor structure in SHARE

Authors: Cristina Portellano-Ortiz ${ }^{1}$, Josep Lluís Conde-Sala ${ }^{1,2}$

\section{Institutional affiliations}

${ }^{1}$ Faculty of Psychology, University of Barcelona, Spain

${ }^{2}$ Girona Biomedical Research Institute (IDIBGI), Research Unit, Healthcare Institute, Salt, Spain

Keywords: Cognition, EURO-D, depressive symptoms, ageing, SHARE, factor analysis

\section{Key points:}

- Poor cognition was associated with older age, lower educational levels, higher economic difficulties and higher depression levels.

- The depression scale (EURO-D) scores were associated with higher levels of loneliness, poorer selfperceived physical health, female gender and poor cognition.

- Poor cognition was associated only with the Motivation factor (EURO-D), while the female gender had a strong significant association with the Suffering factor (EURO-D).

Words. Abstract: 241; text: 3948; Tables: 4 (and a 2suppl.).

\section{Corresponding author:}

\section{Cristina Portellano-Ortiz}

Faculty of Psychology. University of Barcelona

Passeig Vall d'Hebron, 171, 08035 Barcelona, Spain

Tel. (+34) 93 3125814; Fax: (+34) 93 4021368; Email: cristina.portellano@ub.edu 


\section{Abstract}

Objective: The aims of this study were: 1 ) to analyse the relationship between cognition and clinical and sociodemographic variables; 2 ) to explore the relationship between cognitive tests and factors of EURO-D depression scale (Suffering and Motivation); and 3) to determine the relevance of cognition with respect to clinical and sociodemographic variables in the scores of the EURO-D factors.

Method: 63,755 participants in the Survey of Health, Ageing and Retirement in Europe (SHARE) Wave 6 (2015) were included. Instruments: the SHARE study, the EURO-D scale and cognitive tests. Bivariate, correlation and multiple linear regression analyses were performed.

Results: In the regression analysis with cognition, the variables associated with poor cognition were higher age $(\beta=0.29)$, lower educational level $(\beta=-0.26)$, economic difficulties $(\beta=0.17)$ and depression $(\beta=0.10)$. The correlation between cognition and EURO-D factors was weak in Suffering $(r=-0.139)$ and moderate in Motivation $(r=-0.382)$. In the regression analysis with the EURO-D, loneliness, poor self-perceived physical health, female gender and low cognition were associated with higher depression levels. The main differences in the predictor variables of each factor were cognition (Motivation $=-0.248, p<0.001$; Suffering $=0.002, p=$ 0.648 ) and the female sex (Motivation $=0.015, p<0.001$, Suffering $=0.175, p<0.001$ ).

Conclusions: In the EURO-D depression scale, poor cognition was associated with higher scores in the Motivation factor only, while the female gender presented higher scores in the Suffering factor.

Keywords: Cognition, EURO-D, depressive symptoms, ageing, SHARE, factor analysis 


\section{INTRODUCTION}

Due to the ageing population and the increased risk of dementia associated with older age, there is a growing interest in understanding how cognitive function changes in older adults. ${ }^{1}$ Cognitive decline in older age can be pathological or part of the normal ageing process, ${ }^{2}$ and dementia and depression are two of the psychiatric syndromes and neurocognitive disorders that present associated cognitive decline. ${ }^{3}$

Dementia is a major cause of disability and dependence in older adults. ${ }^{4}$ The number of people affected by some type of neurocognitive disorder and/or dementia at global level is estimated to be 35.6 million, ${ }^{5}$ a figure that is expected to reach 60 million by $2030 .{ }^{6}$ The prevalence of depression in dementia is $32 \% .{ }^{7}$

Depression and depressive symptoms are two of the most frequent psychiatric disorders in older adults, with a prevalence ranging from $4.6 \%$ to $9.3 \%$ for severe depression and from $4.5 \%$ to $37.4 \%$ for depressive disorders in people aged 75 and over, depending on the type of study conducted, the population studied and the diagnostic tools used. ${ }^{8}$ The highest rate of depressive symptoms occurs in those aged 80 and over, in institutionalized individuals and those suffering from some kind of dementia. ${ }^{9-12}$

The relationship between cognition and depression has been subject to numerous studies, which have found that older adults with depressive disorders usually present cognitive complaints, and that those with mild cognitive impairment usually suffer from depressive symptoms. ${ }^{13-17}$ Moreover, it should be noted that perception of self-efficacy ${ }^{18}$ and the concept of cognitive reserve ${ }^{19}$ may act as protective factors against cognitive decline and as mediators of depressive symptoms. ${ }^{20,21}$ Likewise, apathy can have a negative impact on the relationship between cognition and depression. ${ }^{22}$

With respect to sociodemographic variables, older age, ${ }^{1,23}$ female gender ${ }^{1,24}$ and not being married ${ }^{25-}$ 27 are related to lower cognitive status. In addition, loneliness is associated with increased depressive symptoms and lower cognitive performance. ${ }^{28,29} \mathrm{Li}$ et al. ${ }^{1}$ found that lower income and higher economic concerns were related to a lower cognitive status. In terms of education, there is an association between lower educational level, a higher risk of depressive symptoms ${ }^{30}$ and lower cognitive performance, ${ }^{31}$ and higher educational levels are related to greater cognitive reserve. ${ }^{19}$ Finally, poorer self-perceived physical 
health, the presence of diseases and activities of daily living (ADL) deficits contribute to depressive symptoms and lower cognition. At the same time, lower cognitive status favours poorer self-perceived physical health. ${ }^{15,}$ 32

The EURO-D ${ }^{33}$ depression scale has been widely used to detect depressive symptoms and associated variables. A factor analysis of the EURO-D in the original scale generated two factors, Affective Suffering and Motivation, which have been validated by further research. ${ }^{34-37}$ Several studies have analysed the variables associated with the two EURO-D factors and found that the female gender is more strongly associated with the Suffering factor, ${ }^{34,36-38}$ and lower verbal fluency with the Motivation factor. ${ }^{36,38}$ Research has addressed the role of age and cognition, especially in the Motivation factor. The hypothesis of late-onset depression and executive function deficits ${ }^{39}$ could explain the higher Motivation factor score in older age and poor cognition. ${ }^{36}$ Given this background, it was considered useful to explore the relationship between general cognition and the Suffering and Motivation factors ${ }^{34}$ of the EURO- $\mathrm{D}^{33}$ depression scale.

The analysis of the effect of cognition and other clinical and sociodemographic variables in the EUROD depression scale and in the factors Suffering and Motivation will allow us to assess their differential contribution to depression. Previous research indicates that a higher score of Motivation factor seems to be related to lower verbal fluency, higher vascular risk and cognitive impairment. We consider it especially relevant to clarify the relevance of cognition, as an independent variable, with respect to other variables of possible confusion (age, gender, education, loneliness or health) in the differences between the factors Suffering and Motivation of the EURO-D depression scale.

Thus, the aims of this study were: 1 ) to analyse the relationship between cognition and clinical and sociodemographic variables; 2) to explore the relationship between cognition subscales and EURO-D depression scale factors (Suffering and Motivation); and 3) to determine the relevance of cognition with respect to other clinical and sociodemographic variables in the EURO-D factor scores. 


\section{METHOD}

\subsection{Design and study population}

Data from the Survey of Health, Ageing and Retirement in Europe (SHARE) Wave 6, conducted in 2015, were used. This transnational, multidisciplinary study carried out in 18 countries (Austria, Germany, Sweden, Spain, Italy, France, Denmark, Greece, Switzerland, Belgium, Israel, the Czech Republic, Poland, Luxembourg, Portugal, Slovenia, Estonia and Croatia) collects information on the health, socioeconomic status and social networks of individuals aged over 50 who are not institutionalized. ${ }^{40,41}$

Data were collected through a computer-assisted personal interview (CAPI) that lasted approximately 90 minutes and took place in participants' homes. ${ }^{40}$ The study comprised 63,755 subjects out of the 67,214 initially available in SHARE Wave 6, following the exclusion of cases in which information was missing for some items in the EURO-D depression scale..$^{33}$

\subsection{Variables and instruments}

Sociodemographic data. Age (average and subgroups), gender, marital status (married, widowed, divorced, never married), years of schooling $(<8,8-12,>12)$, economic difficulties (those making ends meet with great difficulty, with some difficulty, fairly easily, easily).

Data on physical health and diseases. Self-perceived physical health (very good, good, fair, poor), presence of diseases (none, 1, 2, >2), existence of activities of daily living (ADL) deficits (none, 1-2, >2). The diseases included in the variable "presence of diseases" were: heart attack, hypertension, cholesterol, stroke, diabetes, chronic lung disease, cancer, stomach or duodenal ulcer, Parkinson, cataracts, hip fracture or femoral fracture, other fractures, Dementia, other emotional disorders, rheumatoid arthritis, and osteoarthritis/other rheumatism.

In addition, the activities included in the variable "existence of ADL deficits" were: dressing, bathing, eating, getting in or out of bed, using the toilet, preparing a hot meal, shopping for groceries, telephone calls, 
taking medications, and managing money. They were assessed by asking if the participants were able to do them by themselves or not

Loneliness scale. The three-item loneliness scale was used (lack of company, isolation from others, feeling of irrelevance), which indicates the frequency with which feelings of loneliness are experienced (almost never $=1$, sometimes $=2$, almost always $=3$ ), with a total score ranging from 3 to 9 , as each item could range from 1 to $3 .{ }^{42} \mathrm{~A}$ higher score indicates a higher presence of loneliness. In a study by Hughes et al., ${ }^{42}$ the scale produced a moderate Cronbach's alpha (0.72), as in the present study (0.75). The 3-item questionnaire was adapted from the Revised UCLA Loneliness Scale (R-UCLA), after exploratory and confirmatory factor analysis. Both the 3-item loneliness scales and the R-UCLA have been validated and are able to be self-administered. We classified subjects with feelings of loneliness when the overall score was $>3$.

Depressive symptoms. The instrument used was the EURO-D depression scale, ${ }^{33}$ which consists of 12 dichotomous items to indicate the presence or absence of the following symptoms over the last month: depressive symptoms, pessimism, a desire for death, guilt, irritability, tearfulness, fatigue, sleep problems, disinterest, loss of appetite, lack of concentration and lack of enjoyment. The cut-off point for depression is $\geq 4$. The total score ranges from 0 to 12 . Higher scores indicate a higher presence of depressive symptoms. In the EURODEP ${ }^{35}$ study, the scale had a moderate Cronbach's alpha (0.61-0.75), as in the present study (0.71). The present study used the factorial solution from a previous study ${ }^{34}$ that established the presence of two factors in the EURO-D scale: Suffering (composed of the items depressive symptoms, guilt, sleep problems, irritability, fatigue and tearfulness) and Motivation (composed of the items pessimism, disinterest, loss of appetite, lack of concentration and lack of enjoyment).

General cognition. Specific items in the SHARE project were used to assess the cognitive status of participants based on immediate recall (presenting a list of 10 words that should be repeated immediately; range $=0-10$ ), delayed recall (asking for the list of 10 words presented before; range $=0-10$ ), orientation (asking about the day, month, year and the day of the week; range $=0-4$ ), subtraction (asking simple mathematical operations 
to mentally calculate; range $=0-5$ ) and verbal fluency (asking about the maximum number of animals remembered in a given period of time; range $=1-10$ ). A joint scale was created with all items with a total score range of 1 to 39 . The higher the score, the higher the cognition.

\subsection{Statistical analysis}

A descriptive study of the sample was performed using means and standard deviation for the continuous variables and frequencies for the categorical variables. The categorical variables were contrasted with the chi-squared test $\left(\chi^{2}\right)$, while the parametric tests of the $t$-test and ANOVA F-test were used for the continuous variables.

The effect size of the difference between two means was assessed using Cohen's $d$, whose values indicate weak (0.2-0.4), moderate $(0.5-0.8)$ or strong $(>0.8)$ effects. ${ }^{43}$ The difference between several means was determined with eta-squared $\left(\eta^{2}\right)$, whose values indicate weak $(0.01-0.05)$, moderate $(0.06-0.13)$ or strong (>0.14) effects. ${ }^{44}$

Multiple linear regression analysis was adjusted by introducing all independent variables in a single step: age, gender, marital status, schooling, economic difficulties, loneliness, physical health, diseases, ADL deficits and EURO-D factors (Suffering and Motivation). Variables with a high degree of collinearity and/or a low coefficient of contribution were eliminated. The final model included the following variables: age, schooling, economic difficulties, depression (measured with the EURO-D scale), ADL deficits and physical health. A complementary analysis was carried out with the Suffering and Motivation factors by substituting the global EURO-D score. The coefficient of contribution (CC) of each variable was calculated according to the solution suggested by Guilford \& Fruchter: ${ }^{45}$ beta coefficient $x$ correlation coefficient (Pearson) with the dependent variable.

The Pearson correlation coefficient was used to assess the correlation between general cognition and the cognitive tests; and the EURO-D depression scale and associated factors (Suffering and Motivation). To assess the differences between the correlation values, Fisher's $s^{46}$ transformation converted $r$ to $z$. The 
correlation effect sizes were analysed in light of weak (0.20-0.34), moderate $(0.35-0.50)$ and strong $(>0.50)$ values. $^{47}$

To compare the scores of the Motivation (range $=0-5$ ) and Suffering (range $=0-6$ ) factors, the direct scores relating to the clinical and sociodemographic variables were transformed into T scores $(10 z+50)$, since the range of the two factors was different.

Finally, several multivariable regression analyses were adjusted, with and without the general cognition, to assess the influence of the variables on the EURO-D depression scale and the Suffering and Motivation factors.

The level of statistical significance for the hypothesis contrasts was 0.05 two sided. Statistical analysis was performed using SPSS v22.0 for Windows (SPSS Inc., Armonk, NY, USA).

\section{RESULTS}

\subsection{Description of the sample}

The study sample consisted of 63,755 participants with a mean age of $67.5 \pm 9.7$ years. The majority were women (56.2\%), were married (69.0\%), had more than eight years of schooling $(78.8 \%)$ and had no major economic difficulties (61.3\%). The $56.0 \%$ did not feel lonely, presented favourable physical health (61.6\%), had no ADL deficits (86.4\%) and were suffering from one illness or none (51.2\%).

With regard to depression, $27.4 \%$ of the participants scored above the cut-off point for depression (EURO-D: $\geq 4$ ). The overall mean score for depression was $2.4 \pm 2.2$. The Suffering factor presented a higher average score than the Motivation factor $(1.7 \pm 1.5$ vs $0.6 \pm 0.9 ; p<0.001)$.

The mean score of the general cognition was $22.4 \pm 6.7$. Full data are shown in Table 1 .

Table 1 


\subsection{Variables associated with cognition}

The bivariate analysis showed strong associations with effect size $\left(\eta^{2}>13\right)$ between the poor general cognition with higher age and lower educational level. The higher economic difficulties, poorer self-perceived physical health, the presence of diseases, ADL deficits and depressive symptoms were also associated with poor cognition, with a moderate effect size. The other variables examined, i.e. gender, marital status and diseases, showed a lower association with a weak effect size.

The correlation between general cognition and the Motivation factor was higher than that between general cognition and the Suffering factor, although both were significant. Full results are shown in Supplementary table 1.

\subsection{Cognition and variables: multiple linear regression analysis}

The variables that presented a higher association with higher general cognition were younger age ( $\beta=$ -0.29), higher educational level $(\beta=0.26)$, lesser economic difficulties $(\beta=-0.17)$ and a lower depression level $(\beta=-0.10)$. The EURO-D factors had a negative association with general cognition that was more relevant in the Motivation factor $(\beta=-0.20)$ than in the Suffering factor $(\beta=-0.04)$. Full data are shown in Table 2 .

Table 2

\subsection{Correlations between cognition, EURO-D depression scale and factors}

Motivation factor had higher correlation with the cognitive tests than Suffering factor and with EURO-D depression scale. The correlation of general cognition was weak in Suffering $(r=-0.139)$ and moderate in Motivation $(r=-0.382)$, although the correlations were always significant.

In view of the transformed Fisher's ${ }^{46} z$, the main differences in the correlations between the Suffering and Motivation factors appeared in the general cognition score, and in the cognitive tests: verbal fluency and immediate recall. Full data are shown in Table 3.

Table 3 


\subsection{Multivariate regression analysis: EURO-D depression scale, factors and cognition}

Three linear regression analyses were adjusted for the EURO-D depression scale and for each factor, i.e. Suffering and Motivation. All independent variables were introduced in a single step, and those that showed a high degree of collinearity and/or a low contribution coefficient were eliminated, thereby resulting in a final model that included cognition, loneliness, physical health, gender, diseases, ADL deficits and age.

In the EURO-D and in both factors, a higher depression level was associated with higher loneliness and poorer self-perceived physical health. In the Suffering factor, diseases $(\beta=0.127, p<0.001)$ and younger age $(\beta=-0.105, p<0.001)$ also had betas higher than 0.10 , associated with higher depression, while in the Motivation factor, $\mathrm{ADL}$ deficits $(\beta=0.126, p<0.001)$ were more relevant.

The main differences in the associations of the independent variables with respect to both EURO-D factors were non-significance of general cognition in the Suffering factor $(\beta=0.002, p=0.648)$ and significance in the Motivation factor $(\beta=-0.248, p<0.001)$. With respect to females, the opposite occurred, i.e. it was more significant in the Suffering factor $(\beta=0.175, p<0.001)$ than in the Motivation factor $(\beta=$ $0.015, p<0.001)$. In terms of the relevance of the variables in the EURO-D, general cognition occupied fourth position $(\beta=-0.110, p<0.001)$ in relation to the overall score. However, it occupied last position, i.e. it was non-significant, in the Suffering factor and first position in the Motivation factor.

The same regression analysis was repeated without introducing the variable general cognition. There were few changes in the Suffering factor: age continued to have a negative effect $(\beta=-0.101, p<0.001)$ and educational level showed a slightly positive effect $(\beta=0.020, p<0.001)$. In the Motivation factor, loneliness ( $\beta=0.247, p<0.001$ vs $\beta=0.274, p<0.001 ;+0.027)$ and poor self-perceived physical health $(\beta=0.149, p$ $<0.001$ vs $\beta=0.178, p<0.001 ;-+0.029)$ increased, gender significance decreased $(\beta=0.015, p<0.001$ vs. $\beta=$ $0.001, p 0.784 ;-0.014)$, ADL deficits increased $(\beta=0.126, p<0.001$ vs $\beta=0.160, p<0.001 ;+0.034)$, older age changed sign $(\beta=-0.033, p<0.001$ vs $\beta=0.029, p<0.001 ;+0.062)$, and the negative effect of lower educational level increased $(\beta=-0.036, p<0.001$ vs $\beta=-0.108, p<0.001 ;+0.075)$. The complete data are shown in Table 4.

Table 4 
Data regarding age are concordant with those of the bivariate analysis (Supplementary Table 2). Higher age was associated with higher scores in the Motivation factor ( $t=44.7, p<0.001, d=0.47$ ) than in the Suffering factor $(\mathrm{t}=14.1, p<0.001, \mathrm{~d}=0.17)$.

\section{DISCUSSION}

\subsection{Relationship between cognition and clinical and sociodemographic variables}

The first aim of the study was to explore the relationship between clinical and sociodemographic variables and the general cognition of the participants. The analysis showed that the variables most associated with poor cognition were older age, lower educational level, higher economic difficulties and higher depression level. The EURO-D factors Suffering and Motivation, ${ }^{34}$ were also associated with poorer cognition, to a greater extent in the Motivation factor than in the Suffering factor.

These results corroborate previous studies that indicate that older age was associated with poorer cognitive performance ${ }^{1,23}$, fact that some authors explain by the lower physical activity, exercise and cognitive training that is common in older adults. ${ }^{48,49}$ In addition, lower educational levels and the consequent poorer cognitive reserve ${ }^{19}$ would be associated with poorer cognition ${ }^{31}$ and faster cognitive decline. ${ }^{48}$ Similarly, economic difficulties would be related to a higher frequency of depressive symptoms and poorer cognitive performance due to a cumulative effect whereby the deficiencies over the years due to economic difficulties cause poorer access to health services. ${ }^{1,51}$ The stressors inherent to economic concerns would also affect the appearance of depressive symptomatology and affect the neural circuits..$^{52}$ It seems, therefore, that education and economic aspects act as mediators in the influence of older age on cognition, given that the educational level is closely related to occupational complexity and the economic status in adulthood. $^{53}$ 


\subsection{Relationship between cognition and EURO-D factors}

The second aim of the study was to analyse the relationship between cognition and the EURO-D and its factors, i.e. Suffering and Motivation. The analysis showed that the correlations between the cognitive tests and the EURO-D factors were always negative and higher for the Motivation factor, with significant differences between factors in each cognitive test.

The main differential aspects of general cognition between the Suffering and Motivation factors were general cognition, verbal fluency and immediate recall. These subscales, which measure mental flexibility and the capacity to consolidate and recover memories, were the most strongly influenced by depressive symptoms, both in the overall EURO-D score and in the Suffering and Motivation factors. ${ }^{14,34,54}$

Other authors who have used the same EURO-D depression scale have found verbal fluency performance to be more strongly associated with motivational symptoms of depression than with affective suffering symptoms. ${ }^{36-38,55}$ In our study, verbal fluency also presented the highest correlation with the Motivation factor, although the correlations with this factor were higher in all cognitive subscales.

\subsection{Variables associated with the EURO-D and Suffering and Motivation factors}

The third objective of this study was to determine the relevance of cognition with respect to the other clinical and sociodemographic variables in the EURO-D and the Suffering and Motivation factor scores.

Loneliness and health problems were common variables in the EURO-D and Suffering and Motivation factors. The association between higher loneliness and higher depressive scores in both factors might be due to the lack of social interaction ${ }^{28}$ and social support ${ }^{29}$ that people with depression generally experience. With regard to health, in terms of both self-perceived physical condition and ADL deficits and the presence of diseases, our results are consistent with those usually reported in the literature, ${ }^{56-58}$ thus confirming that the poorest perception of health and/or diseases or ADL deficits were associated with a higher presence of depressive symptoms.

The main differences revealed in the analysis were that general cognition was non-significant in the Suffering factor, but significant in the Motivation factor, and gender was more relevant in the Suffering 
factor. Our results corroborate the findings of previous studies, i.e. that poorer cognition was associated with higher depression levels. ${ }^{13-17}$ The most relevant of our findings was that the association between a poor cognition and a greater depression only occurred in the motivation factor. One possible explanation is that the Motivation factor includes some specific cognitive items such as disinterest, lack of concentration or lack of enjoyment, while the items of the Suffering factor are not specifically cognitive. Some authors have hypothesized that vascular depression could explain this stronger association between the motivational factor and poor cognition ${ }^{59}$, while others have suggested that high scores on motivational symptoms would be more present in subjects with mild cognitive impairment ${ }^{60}$ or even be a prodrome of dementia. ${ }^{61}$

A second difference was that women were more relevant in the Suffering factor, according to several studies, $^{34,36-38}$ and usually present higher percentages of widowhood, loneliness and social isolation..$^{35,36,58,62}$ A key topic addressed by several authors is the influence of age and cognition on Motivation factor scores. ${ }^{36,38}$ They consider that Motivation factor scores could be related to the depression-executive dysfunction hypothesis, with the presence of motivation-related symptoms caused by the deterioration of executive function in ageing, ${ }^{39}$ since older age may lead to a reduction in cognitive function, as well as less activity and motivation. ${ }^{37}$ In our study, eliminating cognition from the regression analysis, in the Motivation factor was associated with an increase in ADL deficits and higher age, and therefore the hypothesis that executive deficits are more frequent in age-related depression could be related to higher scores in the Motivation factor. However, while the older age was related to a higher Motivation factor, ${ }^{38}$ the younger age was related to a higher Suffering factor.

It is possible that the differences between the Suffering and Motivation factors are due to a multiplicity of personal and cultural variables (age, education, economic situation, employment, physical exercise, cognition, health, etc.). In a previous study, ${ }^{34}$ a clear differentiation between European countries was observed. In Central and Northern European countries there was a predominance of the Suffering factor, while in Southern European countries there was a predominance of the Motivation factor. 


\subsection{Clinical implications}

Our results corroborate the association between depression and cognitive decline. ${ }^{13-17}$ The presence of depression favours lower cognitive performance, in the same way that cognitive performance influences and conditions the possible presence of depressive symptomatology. Nevertheless, different sociodemographic variables would mediate and modify the type and direction of these associations. It is therefore necessary to assess the presence of both depression and cognitive impairment at the time of diagnosis to establish appropriate therapeutic criteria.

In light of the results of our study and previous research, it would be convenient to specifically assess the Motivation factor items because of their remarkable association with lower cognition and possible cognitive deterioration.

\subsection{Limitations and future research}

An important limitation of our study has been the absence of a clinical examination of the participants regarding depression, as well as not being able to use other psychometric instruments on depression to compare the results.

Given the importance of education in cognition, it would be advisable to carry out further research on the education system in each of the countries of origin of the SHARE participants with a view to assessing this specific aspect. Moreover, given the impact that health has on depression, it would be useful to identify the diseases and ADL deficits that condition self-perception of health status and the associated depression.

Although this is a comprehensive and cross-cutting analysis, a longitudinal study that reflects the differences between countries and/or European regions would be useful. 


\section{CONCLUSIONS}

This analysis showed an association mainly between lower cognitive status and higher age and lower educational levels. Greater economic difficulties and the presence of depressive symptoms were also related to lower cognitive performance.

The scores of the depression scale (EURO-D) were associated with greater loneliness, poorer selfperceived health, female gender and lower cognition.

Regarding the Motivation and Suffering factors, lower cognition was associated with higher scores only in the Motivation factor (EURO-D), while the female gender was associated with higher scores in the Suffering factor (EURO-D). Age presented a different relationship with depression depending on the factor, with lower age being relevant in the Suffering factor and higher age in the Motivation factor. 


\section{ACKNOWLEDGEMENTS}

This paper uses data from SHARE Wave 6 (DOI: 10.6103/SHARE.w6.600).

The SHARE data collection has been primarily funded by the European Commission through FP5 (QLK6-CT2001-00360), FP6 (SHARE-I3: RII-CT-2006-062193, COMPARE: CIT5-CT-2005-028857, SHARELIFE: CIT4-CT2006-028812) and FP7 (SHARE-PREP: N²11909, SHARE-LEAP: º227822, SHARE M4: N²61982). Additional funding from the German Ministry of Education and Research, the Max Planck Society for the Advancement of Science, the U.S. National Institute on Aging (U01_AG09740-13S2, P01_AG005842, P01_AG08291, P30_AG12815, R21_AG025169, Y1-AG-4553-01, IAG_BSR06-11, OGHA_04-064, HHSN271201300071C) and from various national funding sources is gratefully acknowledged (see www.share-project.org). 


\section{REFERENCES}

1. Li LW, Ding D, Wu B, Dong X. Change of cognitive function in U.S. Chinese older adults: a population-based study. J Gerontol A Biol Sci Med Sci. 2017;72(Suppl 1):S5-S10. doi: 10.1093/gerona/glx004

2. Harris M. (2017). Cognitive issues: decline, delirium, depression, dementia. Nurs Clin North Am. 2017;52(3):363-374. doi: 10.1016/j.cnur.2017.05.001

3. American Psychiatric Association. Diagnostic and statistical manual of mental disorders. 5th ed. Arlington (VA): American Psychiatric Association; 2013.

4. Yang L, Jin X, Yan J, et al. Prevalence of dementia, cognitive status and associated risk factors among elderly of Zhejiang province, China in 2014. Age Ageing. 2016;45(5):708-712. doi: 10.1093/ageing/afw088

5. World Health Organization. Dementia: A public Health priority. United Kingdom: World Health Organization; 2012.

6. Klich-Raczka A, Piotrowicz K, Mossakowska M, et al. (2014). The assessment of cognitive impairment suspected of dementia in Polish elderly people: results of the population-based PolSenior Study. Exp Gerontol. 2014;57:233-242. doi: 10.1016/j.exger.2014.06.003

7. Enache D, Winblad B, Aarsland D. Depression in dementia: epidemiology, mechanisms, and treatment. Curr Opin Psychiatry. 2011;24(6):461-472. doi: 10.1097/YCO.0b013e32834bb9d4.

8. Luppa M, Sikorski C, Luck T, et al. Age- and gender-specific prevalence of depression in latest-life - Systematic review and meta-analysis. J Affect Disord. 2012;136(3):212-221. doi: 10.1016/j.jad.2010.11.033

9. Bergdahl E, Gustavsson JM, Kallin K, et al. Depression among the oldest old: the Umeå 85+ study. Int Psychogeriatr. 2005;17(4):557-575. doi: 10.1017/\$1041610205002267

10. Blazer DG, Hybels CF. Origins of depression in later life. Psychol Med. 2005;35(9):1241-1252. doi: $10.1017 /$ S0033291705004411 
11. Bergdahl E, Allard P, Gustafson Y. Depression among the very old with dementia. Int Psychogeriatr. 2011;23(5):756-763. doi: 10.1017/S1041610210002255

12. Conradsson M, Rosendahl E, Littbrand H, Gustafson Y, Olofsson B, Lövheim H. Usefulness of the Geriatric Depression Scale 15-item version among very old people with and without cognitive impairment. Aging Ment Health. 2013;17(5):638-645. doi: 10.1080/13607863.2012.758231

13. Dias FLDC, Teixeira AL, Guimarães HC, et al. Cognitive performance of Community-dwelling oldest-old individuals with major depression: the Pietà study. Int Psychogeriatr. 2017;29(9):15071513. doi: $10.1017 / S 1041610217000850$

14. Riddle M, Potter GG, McQuoid DR, Steffens DC, Beyer JL, Taylor WD. Longitudinal cognitive outcomes of clinical phenotypes of late-life depression. Am J Geriatr Psychiatry. 2017;pii:S10647481(17)30276-2. doi: 10.1016/j.jagp.2017.03.016

15. Yates JA, Clare L, Woods RT. Cognitive Function and Ageing Study: Wales. "You've got a friend in me": can social networks mediate the relationship between mood and MCI? BMC Geriatr. 2017;17(1):144. doi: 10.1186/s12877-017-0542-0

16. Yoon JS, Charness N, Boot WR, Czaja SJ, Rogers WA. Depressive symptoms as a predictor of memory complaints in the PRISM sample. J Gerontol B Psychol Sci Soc Sci. 2017;0(0):1-10. doi: 10.1093/geronb/gbx070

17. Zlatar ZZ, Muniz M, Galasko D, Salmon DP. Subjective cognitive decline correlates with depression symptoms and not with concurrent objective cognition in a clinic-based sample of older adults. J Gerontol B Psychol Sci Soc Sci. 2017;0(0):1-5. doi:10.1093/geronb/gbw207

18. O'Shea DM, Dotson VM, Fieo RA, et al. (2016). Older adults with poor self-rated memory have less depressive symptoms and better memory performance when perceived self-efficacy is high. Int J Geriatr Psychiatry. 2016;31(7):783-790. doi: 10.1002/gps.4392

19. Stern $\mathrm{Y}$. What is cognitive reserve? Theory and research application of the reserve concept. $J$ Int Neuropsychol Soc. 2002;8(3):448-460. 
20. Opdebeeck C, Matthews FE, Wu YT, Woods RT, Brayne C, Clare L. Cognitive reserve as a moderator of the negative association between mood and cognition: evidence from a population-representative cohort. Psychol Med. 2017;19:1-11. doi: 10.1017 /S0033291717001 26X

21. Rusmaully J, Dugravot A, Moatti JP, et al. Contribution of cognitive performance and cognitive decline to associations between socioeconomic factors and dementia: A cohort study. PLoS Med. 2017;14(6):e1002334. doi: 10.1371/journal.pmed.1002334

22. Funes CM, Lavretsky H, Ercoli L, St Cyr N, Siddarth P. Apathy mediates cognitive difficulties in geriatric depression. Am J Geriatr Psychiatry. 2017;pii:S1064-7481(17)30358-5. doi: 10.1016/j.jagp.2017.06.012

23. Gutzmann H, Qazi A. Depression associated with dementia. Z Gerontol Geriatr. 2015;48(4):305311. doi: $10.1007 / \mathrm{s} 00391-015-0898-8$

24. Goveas JS, Espeland MA, Woods NF, Wassertheil-Smoller S, Kotchen JM. Depressive symptoms and incidence of mild cognitive impairment and probable dementia in elderly women: the Women's Health Initiative Memory Study. J Am Geriatr Soc. 2011;59(1):57-66. doi: 10.1111/j.1532-5415.2010.03233.x

25. Helmer C, Damon D, Letenneur L, et al. Marital status and risk of Alzheimer's disease: a French population-based cohort study. Neurology. 1999;53(9):1953-1958. doi: 10.1212/WNL.53.9.1953

26. Van Gelder BM, Tijhuis M, Kalmijn S, Giampaoli S, Nissinen A, Kromhout D. Marital status and living situation during a 5-year period are associated with a subsequent 10 -year cognitive decline in older men: the FINE Study. J Gerontol B Psychol Sci Soc Sci. 2006;61(4):213-219. 10.1093/geronb/61.4.P213

27. Håkansson K, Rovio S, Helkala EL, et al. Association between mid-life marital status and cognitive function in later life: population based cohort study. BMJ. 2009;339:b2462. doi: 10.1136/bmj.b2462 
28. Domènech-Abella J, Lara $\mathrm{E}$, Rubio-Valera $\mathrm{M}$, et al. Loneliness and depression in the elderly: the role of social network. Soc Psychiatry Psychiatr Epidemiol. 2017;52(4):381-390. doi: $10.1007 / \mathrm{s} 00127-017-1339-3$

29. de Brito TRP, Nunes DP, Corona LP, da Silva Alexandre T, de Oliveira Duarte YA. Low supply of social support as risk factor for mortality in the older adults. Arch Gerontol Geriatr. 2017;73:7781. doi: 10.1016/j.archger.2017.07.016

30. Peyrot WJ, Lee SH, Milaneschi Y, et al. The association between lower educational attainment and depression owing to shared genetic effects? Results in $\sim 25,000$ subjects. Mol Psychiatry. 2015;20(6):735-743. doi: 10.1038/mp.2015.50

31. Maurer J. Education and male-female differences in later-life cognition: international evidence from Latin America and the Caribbean. Demography. 2011;48(3):915-930. doi: 10.1007/s13524011-0048-x

32. Godin J, Armstrong JJ, Rockwood K, Andrew MK. Dynamics of frailty and cognition after age 50: why it matters that cognitive decline is mostly seen in old age. I Alzheimer Dis. 2017;58(1):231.242. doi: 10.3233/JAD-161280

33. Prince MJ, Reischies F, Beekman AT, et al. Development of the EURO-D scale - a European Union initiative to compare symptoms of depression in 14 European centres. Br J Psychiatry. 1999;174:330-338. doi: 10.1192/bjp.174.4.330

34. Portellano-Ortiz C, Garre-Olmo J, Calvó-Perxas L, Conde-Sala JL. Factor structure of depressive symptoms using the EURO-D scale in the over-50s in Europe. Findings from the SHARE project. Aging Ment Health. 2017. [Epub ahead of print]. doi: 10.1080/13607863.2017.1370688

35. Guerra M, Ferri C, Llibre J, Prina AM, Prince M. Psychometric properties of EURO-D, a geriatric depression scale: a cross-cultural validation study. BMC Psychiatry. 2015;15:12. doi: $10.1186 /$ s12888-015-0390-4 
36. Castro-Costa E, Dewey M, Stewart R, et al. Prevalence of depressive symptoms and syndromes in later life in ten European countries. The SHARE study. Br J Psychiatry. 2007;191:393-401. doi: 10.1192/bjp.bp.107.036772

37. Verropoulou G, Tsimbos C. Socio-demographic and health related factors affecting depression of the Greek population in later life an analysis using SHARE data. Eur J Ageing. 2007;4(3):171-181. doi: $10.1007 /$ s10433-007-0060-6.

38. Brailean A, Guerra M, Chua KC, Prince M, Prina MA. A multiple indicators multiple causes model of late-life depression in Latin American countries. J Affect Disord. 2015;184:129-136. doi: 10.1016/j.jad.2015.05.053

39. Alexopoulos GS. Depression in the elderly. Lancet. 2005;365(9475):1961-1970. doi: $10.1016 / \mathrm{S} 0140-6736(05) 66665-2$

40. Börsch-Supan A, Brandt M, Hunkler C, et al. Data Resource Profile: The Survey of Health, Ageing and Retirement in Europe (SHARE). Int J Epidemiol. 2013;42(4):992-1001. doi: 10.1093/ije/dyt088

41. Börsch-Supan A. Survey of Health, Ageing and Retirement in Europe (SHARE) Wave 6. Release version: 6.0.0. SHARE-ERIC. Data set; 2017. doi: 10.6103/SHARE.w6.600

42. Hughes ME, Waite L, Hawkley LC, Cacioppo JT. A short scale for measuring loneliness in large surveys: results from two population-based studies. Res Aging. 2004; 26(6):655-672. doi: $10.1177 / 0164027504268574$

43. Cohen J. A power primer. Psychol Bull. 1992;112(1):155-159.

44. Cohen J. (1973). Eta-squared and partial eta-squared in fixed factor ANOVA designs. Educ Psychol Meas. 1973;33(1):107-112. doi:10.1177/001316447303300111

45. Guilford JP, Fruchter B. Fundamental statistics in psychology and education (5th ed.). New York: McGraw-Hill; 1973.

46. Fisher RA. Frequency distribution of the values of the correlation coefficient in samples from an indefinitely large population. Biometrika. 1915;10(4):507-521. doi: 10.2307/2331838 
47. Guyatt GH, King DR, Feeny DH, Stubbing D, Goldstein RS. Generic and specific measurement of health-related quality of life in a clinical trial of respiratory rehabilitation. J Clin Epidemiol. 1999;52(3):187-192.

48. Kirk-Sanchez NJ, McGough EL. Physical exercise and cognitive performance in the elderly: current perspectives. Clin Interv Aging. 2014;9:51-62. doi: 10.2147/CIA.S39506

49. Bherer L. Cognitive plasticity in older adults: effects of cognitive training and physical exercise. Ann N Y Acad Sci. 2015;1337:1-6. doi: 10.1111/nyas.12682.

50. Vandemeulebroecke M, Bornkamp B, Kranhnke T, Mielke J, Monsch A, Quarg P. A longitudinal item response theory model to characterize cognition over time in elderly subjects. CPT Pharmacometrics Syst Pharmacol. 2017. [Epub ahead of print] doi: 10.1002/psp4.12219.

51. Chiao C, Weng L. Mid-life socioeconomic status, depressive symptomatology and general cognitive status among older adults: inter-relationships and temporal effects. BMC Geriatr. 2016;16: 88. doi: 10.1186/s12877-016-0257-7

52. Sapolsky RM. Glucocorticoids, stress, and their adverse neurological effects: relevance to aging. Exp Gerontol. 1999;34:721-732. doi: 10.1016/\$0531-5565(99)00047-9

53. González MF, Facal D, Juncos-Rabadán O, Yanguas J. Socioeconomic, emotional, and physical execution variables as predictors of cognitive performance in a Spanish sample of middle-aged and older Community-dwelling participants. Int Psychogeriatr. 2017;1-12. doi: $10.1017 /$ S1041610217001144

54. Yatawara C, Lim L, Chander R, Zhou J, Kandiah N. Depressive symptoms influence global cognitive impairment indirectly by reducing memory and executive function in patients with mild cognitive impairment. J Neurol Neurosurg Psychiatry. 2016;87(12):1375-1383. doi: 10.1136/jnnp-2016314191

55. Brailean A, Comijs HC, Aartsen MJ, et al. Late-life depression symptom dimensions and cognitive functioning in the Longitudinal Aging Study Amsterdam (LASA). J Affect Disord. 2016;201:171178. doi: 10.1016/j.jad.2016.05.027 
56. Kim D. The effects of a combined physical activity, recreation, and art and craft program on ADL, cognition, and depression in the elderly. J Phys Ther Sci. 2017;29(4):744-747. doi: 10.1589/jpts.29.744

57. Portellano-Ortiz C, Garre-Olmo J, Calvó-Perxas L, Conde-Sala JL. Symptoms of depression and associated factors in persons aged 50 and over in Europe and Israel: analysis of data from the SHARE project. Int J Geriatr Psychiatry. 2016;31(11):1250-1251. doi: 10.1002/gps.4467

58. Saiz D, Rodríguez M, García M, García C, Prieto R, Saiz-Ruiz J. Diferencias de sexo en el trastorno depresivo mayor: síntomas somáticos y calidad de vida. Rev Psiquiatr Salud Ment. 2009;2:119127. doi: $10.1016 / \mathrm{S} 1888-9891(09) 72402-4$

59. Kooistra M, Zuithoff NPA, Gool AM, et al. Cognitive performance and the course of depressive symptoms over 7 years of follow-up: the SMART-MR study. Psychol Med. 2015;45(8):1741-1750. doi: $10.1017 /$ S0033291714002864

60. Kumar R, Jorm AF, Parslow RA, Sachdev PS. Depression in mild cognitive impairment in a community sample of individuals 60-64 years old. Int Psychogeriatr. 2006;18(3):471-480. doi: $10.1017 /$ S1041610205003005

61. Bartolini M, Coccia M, Luzzi S, Provinciali L, Ceravolo MG. Motivational symptoms of depression mask preclinical Alzheimer's disease in elderly subjects. Dement Geriatr Cogn Disord. 2005;19(1):31-36. doi:10.1159/000080968

62. Van de Velde S, Bracke P, Levecque K. Gender differences in depression in 23 European countries. Cross-national variation in the gender gap in depression. Soc Sci Med. 2010;71(2):305-313. doi: 10.1016/j.socscimed.2010.03.035 
TABLE 1 Clinical and sociodemographic data

\begin{tabular}{|c|c|c|c|c|c|}
\hline Characteristic & Category & Value & Characteristic & Category & Value \\
\hline \multirow[t]{3}{*}{ Age } & mean (SD) $\quad 67$ & 7.5 (9.7) & Diseases & None & 23.0 \\
\hline & Range & $50-105$ & & 1 & 28.2 \\
\hline & & & & 2 & 21.3 \\
\hline \multirow[t]{5}{*}{ Age groups } & $<60$ years & 24.0 & & $>2$ & 27.4 \\
\hline & $61-70$ years & 36.3 & & & \\
\hline & $71-80$ years & 26.1 & ADL deficits & None & 86.4 \\
\hline & $\geq 80$ years & 13.6 & & $1-2$ & 9.1 \\
\hline & & & & $>2$ & 4.5 \\
\hline \multirow[t]{3}{*}{ Gender } & Male & 43.8 & & & \\
\hline & Female & 56.2 & EURO-D & mean (SD) & $2.4(2.2)$ \\
\hline & & & & Range & $0-12$ \\
\hline \multirow[t]{5}{*}{ Marital status } & Married & 69.0 & & $\geq 4$ points & 27.4 \\
\hline & Widowed & 15.5 & Suffering $\mathrm{f}$. & mean (SD) & $1.7(1.5)$ \\
\hline & Divorced & 9.9 & & Range & $0-6$ \\
\hline & Never married & 5.6 & Motivation $\mathrm{f}$. & mean (SD) & $0.6(0.9)$ \\
\hline & & & & Range & $0-5$ \\
\hline \multirow[t]{4}{*}{ Education (years) } & $>12$ & 33.5 & monumage & & \\
\hline & $8-12$ & 45.3 & COGNITION & mean (SD) & $22.4(6.7)$ \\
\hline & $<8$ & 21.2 & & Range & $1-39$ \\
\hline & & & Immediate recall & mean (SD) & $5.3(1.7)$ \\
\hline \multirow[t]{5}{*}{ Economic diffic. } & Great difficulty & 12.3 & & Range & $0-10$ \\
\hline & Some difficulty & 26.3 & Delayed recall & mean (SD) & $3.9(2.1)$ \\
\hline & Fairly easily & 26.9 & & Range & $0-10$ \\
\hline & Easily & 34.4 & Orientation & mean (SD) & $3.8(0.4)$ \\
\hline & & & & Range & $0-4$ \\
\hline \multirow[t]{3}{*}{ Loneliness } & Yes & 44.0 & Subtraction & mean (SD) & $4.1(1.4)$ \\
\hline & No & 56.0 & & Range & $0-5$ \\
\hline & & & Fluency & mean $(S D)$ & $5.2(2.8)$ \\
\hline \multirow[t]{4}{*}{ Self-perceived healt } & Very good & 25.2 & & Range & $1-10$ \\
\hline & Good & 36.4 & & & \\
\hline & Fair & 28.6 & & & \\
\hline & Poor & 9.8 & & & \\
\hline
\end{tabular}

Data columns are \% unless otherwise stated. R, Range; EURO-D = Depression; ADL, Activities of daily living 
TABLE 2 General cognition and variables. Multivariate regression analysis

\begin{tabular}{lllllllll} 
Characteristics & $\mathbf{r}^{2}=\mathbf{0 . 3 5 6}$ & $\mathbf{B}$ & (SE) & $\mathbf{6}$ & $\boldsymbol{t}$ & $\boldsymbol{p}$ & $\boldsymbol{r}$ & $\mathbf{C C}(\%)$ \\
\hline Age & - = less & $-0.20(0.00)$ & -0.29 & -84.5 & $<\mathbf{0 . 0 0 1}$ & -0.40 & 12.0 \\
Education (years) & $+=$ more & $0.41(0.00)$ & 0.26 & 77.2 & $<\mathbf{0 . 0 0 1}$ & 0.42 & 11.4 \\
Economic diffic. & $-=$ less & $-1.10(0.02)$ & -0.17 & -48.9 & $<\mathbf{0 . 0 0 1}$ & -0.28 & 4.8 \\
EURO-D & $-=$ less & $-0.30(0.01)$ & -0.10 & -27.2 & $<\mathbf{0 . 0 0 1}$ & -0.27 & 2.8 \\
Deficits ADL & $-=$ less & $-0.59(0.02)$ & -0.09 & -26.3 & $<\mathbf{0 . 0 0 1}$ & -0.26 & 2.4 \\
Self-perceived health & $+=$ better & $0.49(0.02)$ & 0.07 & 18.1 & $<\mathbf{0 . 0 0 1}$ & 0.32 & 2.2 \\
F (df), $p$ & & $5632.6(6-61,105)$ & & $<\mathbf{0 . 0 0 1}$ & & \\
Collinearity: Tol. / VIF. & & $0.71-0.86 / 1.15-1.40$ & & & & & \\
\hline
\end{tabular}

Replacing the EURO-D by the factors

\begin{tabular}{|c|c|c|c|c|c|c|c|}
\hline & $r^{2}=0.38$ & & & & & & \\
\hline Suffering factor & $-=$ less & $-0.19(0.01)$ & -0.04 & -12.9 & $<0.001$ & -0.13 & 0.6 \\
\hline Motivation factor & $-=$ less & $-1.41(0.02)$ & -0.20 & -56. & $<0.001$ & -0.37 & 7.7 \\
\hline
\end{tabular}

$F$, ANOVA; $r^{2}$, Coefficient of determination; B, Unstandardized coefficient; SE, Standard error; $\beta$, Standardized beta coefficient $\geq 0.04$; $t$, Student's $t$-test; $r$, Pearson correlation; CC, coefficient of contribution (\%), [( $\beta . r) \times 100)]$; Tol, Tolerance; VIF, Variance inflation factor. $p$-values $<0.05$ are shown in bold

Dependent variable, General cognition. EURO-D, Depression scale; ADL, Activities of daily living. 
TABLE 3 Correlations between cognitive tests, EURO-D and factors

$\begin{array}{llll}\text { EURO-D } & \text { 1. Suffering } & \text { 2. Motivation } \\ r & p & p\end{array}$

\section{Cognition subscales}

$\begin{array}{lllllll}\text { Immediate recall } & -0.211 & <\mathbf{0 . 0 0 1} & -0.097 & <0.001 & -0.300 & <0.001 \\ \text { Delayed recall } & -0.196 & <\mathbf{0 . 0 0 1} & -0.093 & <0.001 & -0.277<0.001 \\ \text { Orientation } & -0.179 & <\mathbf{0 . 0 0 1} & -0.096 & <\mathbf{0 . 0 0 1} & -0.234<0.001 \\ \text { Subtraction } & -0.248 & <\mathbf{0 . 0 0 1} & -0.150<\mathbf{0 . 0 0 1} & -0.301<0.001 \\ \text { Fluency } & -0.219 & <\mathbf{0 . 0 0 1} & -0.104<\mathbf{0 . 0 0 1} & -0.311<\mathbf{0 . 0 0 1} \\ \text { General cognition } & -0.279 & <\mathbf{0 . 0 0 1} & -0.139<\mathbf{0 . 0 0 1} & -0.382<\mathbf{0 . 0 0 1}\end{array}$

$r=$ Pearson correlation; $p$-values $<0.05$ are shown in bold. $z=$ Fisher transformation $r$ to $z$ (Fisher, 1915). Effect size of correlations: weak, 0.20-0.34; moderate, 0.35-0.50; strong, >0.50 (Guyatt et al., 1999). EURO-D = Depression scale; Factor 1 (Suffering) and Factor 2 (Motivation). 
TABLE 4 EURO-D, Suffering and Motivation factors, and variables. Multivariate regression analysis

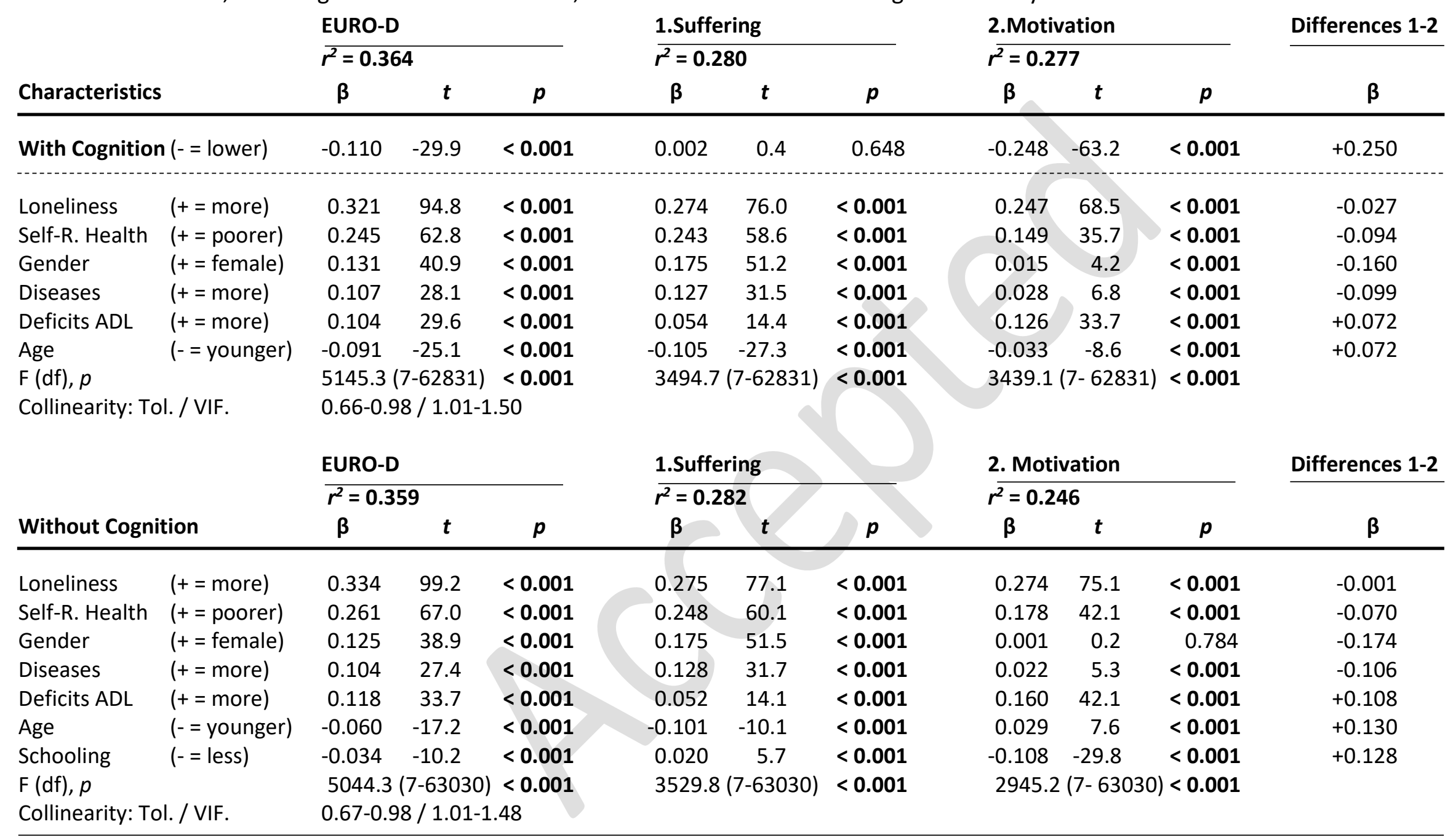

$F$, ANOVA; $r^{2}$, Coefficient of determination; $\beta$, Standardized coefficient; SE, Standard error; $t$, Student's $t$ test; Tol, Tolerance; VIF, Variance Inflation Factor. $p$-values $<0.05$ are shown in bold. EURO-D, Depression scale; ADL, Activities of daily living. Cognition, General cognition 
SUPPLEMENTARY TABLE 1 General cognition scores in the variables

\begin{tabular}{|c|c|c|c|c|c|}
\hline Characteristic & Category & Mean (SD) & Characteristic & Category & Mean (SD) \\
\hline \multirow[t]{6}{*}{ Age } & $<60$ years & $25.3(5.7)$ & Loneliness & Yes & $21.2(6.9)$ \\
\hline & $61-70$ years & $23.8(5.9)^{\mathrm{a}}$ & & No & $23.5(6.3)$ \\
\hline & $71-80$ years & $21.0(6.3)^{b, d}$ & & $\mathrm{t}(p) d$ & $(<0.001) 0.34$ \\
\hline & $\geq 80$ years & $16.6(6.6)^{c, e, f}$ & & & \\
\hline & $F(p) \eta^{2}$ & $(<0.001) 0.17$ & Self-p. health & Very good & $25.3(5.7)$ \\
\hline & & & & Good & $23.0(6.2)^{\mathrm{a}}$ \\
\hline \multirow[t]{3}{*}{ Gender } & Male & $22.3(6.3)$ & & Fair & $20.7(6.7)^{b, d}$ \\
\hline & Female & $22.5(7.0)$ & & Poor & $18.1(7.2)^{c, e, f}$ \\
\hline & $\mathrm{t}(p) d$ & $(<0.001) 0.03$ & & $F(p) \eta^{2}$ & $(<0.001) 0.10$ \\
\hline \multirow[t]{5}{*}{ Marital status } & Married & $22.9(6.4)$ & Diseases & None & $24.4(6.1)$ \\
\hline & Widowed & $19.3(7.2)^{\mathrm{a}}$ & & 1 & $23.0(6.5)^{a}$ \\
\hline & Divorced & $24.2(6.2)^{b, d}$ & & 2 & $22.1(6.6)^{b, d}$ \\
\hline & Never married & $22.8(6.9)^{e, f}$ & & $>2$ & 20.5 (6.9) c, e,f \\
\hline & $\mathrm{F}(p) \eta^{2}$ & $(<0.001) 0.04$ & & $\mathrm{~F}(p) \eta^{2}$ & $(<0.001) 0.04$ \\
\hline \multirow[t]{4}{*}{ Education } & $>12$ years & $25.6(5.6)$ & ADL deficits & None & $23.1(6.3)$ \\
\hline & $8-12$ years & $22.2(6.0)^{a}$ & & $1-2$ & $19.3(7.0)^{a}$ \\
\hline & $<8$ years & $17.9(6.8)^{b, d}$ & & $>2$ & $15.1(7.5)^{b, d}$ \\
\hline & $F(p) \eta^{2}$ & $(<0.001) 0.16$ & & $F(p) \eta^{2}$ & $(<0.001) 0.08$ \\
\hline \multirow[t]{5}{*}{ Economic diffic. } & Great difficulty & $18.9(6.7)$ & EURO-D & $<4$ points & $23.4(6.2)$ \\
\hline & Some difficulty & $21.2(6.4)^{a}$ & 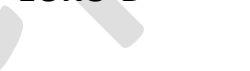 & $\geq 4$ points & $20.0(7.3)$ \\
\hline & Fairly easily & $22.9(6.4)^{b, d}$ & & $\mathrm{t}(p) d$ & $(<0.001) 0.50$ \\
\hline & Easily & $24.5(6.1)^{c, e, f}$ & Suffering $f$. & $r(p)$ & $-0.13(<0.001)$ \\
\hline & $\mathrm{F}(p) \eta^{2}$ & $(<0.001) 0.07$ & Motivation $\mathrm{f}$. & $r(p)$ & $-0.38(<0.001)$ \\
\hline
\end{tabular}

$F=$ ANOVA; Significant with Bonferroni post-hoc contrasts: ${ }^{\mathrm{a}} 1-2,{ }^{\mathrm{b}} 1-3,{ }^{\mathrm{c}} 1-4,{ }^{\mathrm{d}} 2-3,{ }^{\mathrm{e}} 2-4,{ }^{\mathrm{f}} 3-4 ; t=$ Student's $t-$ test; $r$, Pearson correlation; Eta-squared $\left(\eta^{2}\right)=$ weak $(<0.05)$, moderate $(0.06-0.13)$, strong $(>0.13)$; Cohen's $d(d)=$ weak $(<0.50)$, moderate $(0.50-0.80)$, strong $(>0.80)$. $p$-values $<0.05$ are shown in bold EURO-D = Depression scale; ADL, Activities of daily living. 
SUPPLEMENTARY TABLE 2. Suffering and Motivation factors of the EURO-D scale and variables

$\frac{\text { F. Suffering }}{\text { Mean (SD) }}$

\section{Age (years)}

1. $<80$

4. $\geq 80$ :

$t(p) d$

\section{Cognition (scores)}

1. $28-39$

2. $24-27$

3. $19-23$

4. 0.18

$F(p) n^{2}$

Schooling (years)

1. $>12$

2. $8-12$

3. $<8$

$F(p) n^{2}$

\section{Loneliness (scores)}

1. No

2. Yes

$t(p) d$

Self-p. health (groups)

1. Very good

2. Good

3. Fair

4. Poor

$F(p) n^{2}$

\section{Gender}

1. Male

2. Female

$t(p) d$

ADL (deficits)

1. None

2. 1-2

3. $\geq 2$

$F(p) n^{2}$

Diseases

1. None

2. 1

3. 2

4. $>2$

$F(p) n^{2}$

Economic diffic.

1. Easily

2. Fairly easily

3. Some difficulty

4. Great difficulty $F(p) n^{2}$
$49.7(10.0)$

$51.4(9.6)$

$14.1(<0.001) 0.17$

$48.7(9.5)$

$49.2(9.6)^{\mathrm{a}}$

$49.7(9.9)^{b, d}$

$52.0(10.3)^{c, e, f}$

$349.9(<0.001) 0.01$

$49.1(9.6)$
$50.1(10.0)^{\mathrm{a}}$
$51.0(10.3)^{\mathrm{b}, \mathrm{d}}$
$157.0(<0.001) 0.00$

$47.2(8.7)$

$53.5(10.3)$

$82.7(<0.001) 0.66$

$45.7(8.0)$

$48.4(9.1)^{\mathrm{a}}$

$52.8(10.0)^{\mathrm{b}, \mathrm{d}}$

$58.5(9.7)^{c, e, f}$

$3692.2(<0.001) 0.14$

$47.4(8.7)$

$51.9(10.4)$

$57.9(<0.001) 0.47$

$49.0(9.6)$

$55.2(10.0)^{\mathrm{a}}$

$57.8(9.8)^{\mathrm{b}, \mathrm{d}}$

$2076.4(<0.001) 0.06$

$46.3(8.4)$

$48.8(9.4)^{\mathrm{a}}$

$50.4(9.8)^{\mathrm{b}, \mathrm{d}}$

$53.9(1.6)^{c, e, f}$

$1835.3(<0.001) 0.08$

$48.2(9.1)$
$49.1(9.5)^{\mathrm{a}}$
$51.0(10.3)^{\mathrm{b}, \mathrm{d}}$
$54.1(10.9)^{\mathrm{c}, \mathrm{e}, \mathrm{f}}$
$779.6(<0.001) 0.03$

F. Motivation

Mean (SD)

$49.2(9.8)$

$54.5(12.8)$

$44.7(<0.001) 0.47$

$46.6(6.3)$

$47.7(7.3)^{\mathrm{a}}$

$49.4(8.8)^{\mathrm{b}, \mathrm{d}}$

$55.3(12.8)^{c, e, f}$

$2825.1(<0.001) 0.11$

$47.8(7.8)$

$49.8(9.6)^{\mathrm{a}}$

$53.6(12.4)^{\mathrm{b}, \mathrm{d}}$

$1454.6(<0.001), 0.04$

$47.7(7.6)$

$52.8(11.7)$

$65.3(<0.001) 0.51$

$46.6(6.5)$

$48.2(7.9)^{\mathrm{a}}$

$51.9(10.7)^{b, d}$

$59.4(14.0)^{c, e, f}$

$3385.1(<0.001) 0.13$

$49.4(9.3)$

$50.4(10.4)$

$12.5(<0.001) 0.10$

$48.8(8.7)$

$55.0(10.0)^{\mathrm{a}}$

$61.9(14.7)^{\mathrm{b}, \mathrm{d}}$

$3484.3(<0.001) 0.09$

$47.3(7.2)$

$48.9(8.9)^{\text {a }}$

$50.1(9.9)^{b, d}$

$53.1(12.0)^{c, e, f}$

$1038.8(<0.001) 0.04$

$47.5(7.4)$

$48.9(8.7)^{\mathrm{a}}$

$51.0(10.4)^{b, d}$

$55.6(13.3)^{c, e, f}$

$1476.2(<0.001) 0.06$
Differences in $\mathrm{T}$ scores

$t \quad p \quad d$

$-9.8<0.001 \quad 0.05$

$22.1<0.001 \quad 0.27$

$\begin{array}{lll}-27.6 & <0.001 & 0.26\end{array}$

$\begin{array}{lll}-17.5<0.001 & 0.17\end{array}$

$\begin{array}{lll}-2.9 & 0.004 & 0.03\end{array}$

$34.8<0.001 \quad 0.28$

$\begin{array}{ccc}-17.8<0.001 & 0.14\end{array}$

$-5.0<0.001 \quad 0.03$

$25.6<0.001 \quad 0.22$

$10.2<0.001 \quad 0.06$

$-9.4<0.001 \quad 0.06$

$13.0<0.001 \quad 0.12$

$\begin{array}{lll}-2.7 & 0.006 & 0.02\end{array}$

$-10.0<0.001 \quad 0.08$

$\begin{array}{lll}5.4<0.001 & 0.07\end{array}$

$32.6<0.001 \quad 0.22$

$-25.2<0.001 \quad 0.14$

$\begin{array}{lll}-4.1<0.001 & 0.02\end{array}$

$\begin{array}{lll}-1.3 & 0.178 & 0.02\end{array}$

$\begin{array}{lll}14.7<0.001 & 0.32\end{array}$

$\begin{array}{lll}13.3<0.001 & 0.12\end{array}$

$\begin{array}{lll}2.0 & 0.041 & 0.01\end{array}$

$\begin{array}{lll}-2.8 & 0.005 & 0.03\end{array}$

$-8.8<0.001 \quad 0.07$

$\begin{array}{rlr}-9.4<0.001 & 0.08\end{array}$

$\begin{array}{lll}-2.2 & 0.024 & 0.02\end{array}$

$\begin{array}{lll}0.6 & 0.540 & 0.00\end{array}$

$10.2<0.001 \quad 0.12$

$F=$ ANOVA; Bonferroni post-hoc contrasts: ${ }^{\mathrm{a}} 1-2,{ }^{\mathrm{b}} 1-3,{ }^{\mathrm{c}} 1-4, \mathrm{~d} 2-3,{ }^{\mathrm{e}} 2-4,{ }^{\mathrm{f}} 3-4$; Eta-squared $\left(\eta^{2}\right)=$ weak $(<0.05)$, medium (0.06 - 0.13), strong (>0.13); $t=$ Student's $t$-test; Cohen's $d(d)=$ weak $(<0.5)$, medium $(0.5-0.8)$, strong $(>0.8)$. Effect size medium and strong in bold. Differences in T scores: negative sign indicates higher scores in Suffering. 